https://dx.doi.org/10.4314/jpb.v17i2.6

Vol. 17 no. 2, pp. 121-130 (September 2020)

http://ajol.info/index.php/jpb
Journal of

PHARMACY AND

BIORESOURCES

\title{
Antimicrobial and wound healing properties of the methanol extract of Ficus platyphylla Del. (Moraceae) stem bark
}

\author{
Azeez Raji SHEIDU ${ }^{*}$, Abdulkadir Umar ZEZI' ${ }^{\text {, Abubakar AHMED }}$, Ben Ahmed \\ CHINDO $^{3}$, Garba Mohammed MAGAJI ${ }^{1}$ \\ ${ }^{I}$ Department of Pharmacology and Therapeutics; ${ }^{2}$ Department of Pharmacognosy and Drug Development; \\ Ahmadu Bello University, Zaria. Nigeria. ${ }^{3}$ Department of Pharmacology and Toxicology, Kaduna State \\ University, Kaduna. Nigeria.
}

Received 27 $7^{\text {th }}$ March 2020; Accepted $3^{\text {rd }}$ August 2020

\begin{abstract}
Ficus platyphylla $(\mathrm{Fp})$ has been used in Nigerian traditional medicine for the management of pain, ulcer, wound, epilepsy and inflammation. The efficacy of its gum from the stem bark for the management of wound has been widely acclaimed among the Hausa communities of Northern Nigeria and therefore, this study was aimed at examining the antimicrobial and wound healing potential of methanol extract of $F$. platyphylla stem bark (MEFpSB) in order to provide scientific basis for its antimicrobial and wound healing properties. Preliminary phytochemical screening was done and antimicrobial activity using some pathogenic micro-organisms were evaluated following its wound healing effectiveness in Wistar rats using the model of superficial skin excision wound. Data were analysed using one-way analysis of variance (ANOVA) followed by Dunnet's t-test. The results of preliminary phytochemical screening revealed the presence of carbohydrate, cardiac glycosides, saponins, flavonoids, triterpenes, tannins, alkaloids with anthraquinones absent. The extract showed antimicrobial activity on Staphylococcus aureus, Corynebacterium ulcerans, Escherichia coli, Klebsiella pneumonia and Salmonella typhi and significant $(p<0.05, p<0.001)$ decrease in wound measurement for 11 days. This study demonstrated that MEFpSB possesses antimicrobial activity with wound healing properties that justifies the ethno-medicinal use of the plant in wound/ulcer healings.
\end{abstract}

Keywords: Wound healing; Antimicrobial; Ficus platyphylla; Formulation; Topical

\section{INTRODUCTION}

Ficus platyphylla with a common name broadleaf fig is a tree with a heavily branched, rather dense, spreading crown that can grow up to 25 metres tall. The plant often begins life as an epiphyte which grows in the branch of another tree and as it gets older, it sends down aerial roots which when they reach the ground quickly form roots and become much thicker and more vigorous. They supply nutrients to the fig, allowing it to grow faster than the host tree. The aerial roots gradually encircle the host tree, preventing its main trunk from expanding, whilst at the same time the foliage smothers the foliage of the host. Eventually the host dies, leaving the fig to carry on growing without competition [1]. The plant (fig) has a unique form of fertilization where each species relies on a single, highly specialized species of wasp that is itself totally dependent upon the species in order to breed. The plant produces three types of flower namely the male, a long-

\footnotetext{
*Correspondence. E-mail: loneumajene4real@yahoo.com Tel: +234-8035927240.

ISSN 0189-8442

(cc) EY-Ne Published by Faculty of Pharmaceutical Sciences, University of Jos, Nigeria. Under the Creative
} Commons Attribution-NonCommercial 4.0 International License. https://creativecommons.org/licenses/by-nc/4.0/ 
styled female and a short-styled female flower, often called the gall flower which are contained within the structure [2]. It is commonly harvested from the wild for local use of its latex, which can be used as a base for chewing gum or to make a good quality rubber [3]. The plant also supplies edible fruits, fibre, dyestuff and tannins. A decoction of the bark is sometimes used in the treatment of leprosy and stomach pins while the decoction of the leafy branch tips is said to be an antidote to arrow poisoning $[4,5]$.

Traditional medicine has become a potential therapeutic agent for various communities around the world as primary health care to address their healthcare needs and concerns $[6$, 7] and this encompasses all kinds of folk medicine, unconventional medicine and indeed any kind of therapeutically available method that had been taken over from the fore fathers [8]. The plant $F$. platyphyalla has been used in Nigeria's folk medicine to manage epilepsy, depression, psychosis, pain and inflammation for many years, and their efficacies are widely acclaimed among the rural communities of Northern Nigeria where it is called locally, 'Gamji' [9]. High performance liquid chromatography (HPLC) and preliminary phytochemical screening of the methanol extract of $F$. platyphylla stem bark have revealed the presence of saponins, flavonoids and tannins [10]. Previous studies have also revealed the analgesic and antiinflammatory effects of the methanol extract of $F$. platyphylla stem bark in different assays including acetic-acid induced writhing, formalin-induced nociception, and albumininduced oedema in mice [11]. The behavioural and anticonvulsant effects of the standardized extract of $F$. platyphylla stem bark have also been reported [12]. Studies have also revealed that the oral administration of the methanol extract of $F$. platyphylla stem bark is safe in rodents [13]. F. platyphyalla (Fp) haven been shown to possess some bioactive constituents like tannins, saponins and flavonoids with anti- inflammatory potential and relatively safe from its previous toxicological studies. The antioxidant and hepatoprotective potential of this plant have also been demonstrated suggesting that MEFpSB can be utilized as a natural source to protect the liver in hepatotoxin liver injury [14]. Review of literature shows that there is no scientific report on antimicrobial and wound healing properties of the plant and therefore, the present study was aimed at providing scientific basis on the use of $F$. platyphylla stem bark in management of ulcer and wound.

\section{EXPERIMENTAL}

Animals. Wistar rats of both sexes weighing 140-200 $\mathrm{g}$ were obtained from and housed in the Animal house, Department of Pharmacology and Therapeutics, A.B.U, Zaria under room temperature. They were all kept in plastic cages. The animals were fed on Vital Grower feeds (Vital feeds, Jos-Plateau State) and water ad libitum. All the experimental procedures followed the ethical guidelines for the care and use of laboratory animals as provided and approved by Ahmadu Bello University Research Policy (Revised, 2010) and accepted internationally (NIH 1985, Revised 1996).

Drugs and chemicals. DPPH (Sigma-Aldrich, Germany), Chloroform (Sigma Chemical Co. USA), $1 \%$ Silver sulphadiazine (Salutas Pharma GmbH, Germany), L-Ascorbic acid(Sigma-Aldrich Co. LLC), Methanol (Synthetic colour chemical Industry, India), Molisch's reagent, Concentrated Sulphuric acid $\left(\mathrm{H}_{2} \mathrm{SO}_{4}\right)$ (BDH Ltd Poole, England), Concentrated hydrochloric acid (BDH Ltd Poole, England), Ferric Chloride (BDH Ltd Poole, England), Silymarin tablets $140 \mathrm{mg}$ film coated tablet (Micro Labs Ltd, India) and Lidocaine Injection $2 \%$ (Erica Life Science Ltd. UK).

Plant material. The plant was collected in Zaria, Kaduna state, Nigeria (Latitude $11^{\circ} 06^{\prime}$ 
40.61 ' $\mathrm{N}$ and Longitude $7^{\circ} 43^{\prime} 21.72^{\prime \prime} \mathrm{E}$ ) and was identified and authenticated by Mallam I. Muazzam of the Department of Medicinal Plant Research and Traditional Medicine, National Institute of Pharmaceutical Research and Development (NIPRD), Abuja. A voucher specimen (No. 4035) was deposited at NIPRD Herbarium for future reference.

Preparation of plant extract. The $F$. platyphylla $(\mathrm{Fp})$ stem bark was freed from sand particles by carefully scrapping with a spatula. It was chopped to pieces, air dried and milled into coarse powder using pestle and mortar. Extraction was carried out by cold maceration of $500 \mathrm{~g}$ of the coarse powder with $2.5 \mathrm{~L}$ of 70 $\% \mathrm{~V} / \mathrm{v}$ aqueous methanol for $72 \mathrm{~h}$, with constant shaking using the Gesellschaft für Labortechnik (GFL shaker No. $3017 \mathrm{mbH}$, Germany). The resultant mixture was filtered using Whatman filter paper (No.1) and the filtrate was evaporated to dryness in vacuo at $40^{\circ} \mathrm{C}$ using rotary evaporator to give a yield of $25 \% \mathrm{w} / \mathrm{w}$ of the extract. Aliquot portions of the extract were weighed and dissolved in distilled water for use in the study.

Phytochemical screening. The preliminary phytochemical screening of the plant was carried out using standard method for the presence of phytochemical constituents [15]. Molisch's test was used to test for carbohydrate. Keller-Killiani and Kedde's test were used for cardiac glycosides. Frothing's test for saponins, Liebermann-Burchard's for steroids and triterpenes. Shinoda and sodium hydroxide test were used for flavonoids. Lead sub-acetate and ferric chloride test were used for tannins and Mayer's, Dragendorff's and Wagner's test were used for alkaloids [15].

Acute toxicity studies. $\mathrm{LD}_{50}$ determination was conducted using Lorke's method [16] for both intra-peritoneal and oral routes in rats. This method was carried out in two phases. In the first phase, 3 rats per group of different weights were treated with the methanol extract of Fp stem bark at a dose of $10 \mathrm{mg} / \mathrm{kg}, 100$ $\mathrm{mg} / \mathrm{kg}$ and $1000 \mathrm{mg} / \mathrm{kg}$ body weight orally and were observed for signs of toxicity and death for 24 hours. Based on the results of the first stage, another set of animals $(n=1)$ were treated with four (4) more specific doses of the extract at $1000 \mathrm{mg} / \mathrm{kg}, 1600 \mathrm{mg} / \mathrm{kg}, 2900 \mathrm{mg} / \mathrm{kg}$, and $5000 \mathrm{mg} / \mathrm{kg}$ body weight respectively and observed for signs of toxicity and mortality for $24 \mathrm{~h}$. The procedure was also repeated for intra-peritoneal route (i.p.). The $\mathrm{LD}_{50}$ value was determined by calculating the geometric mean of the highest non-lethal dose (0/1) and lowest lethal dose (1/1) as shown in the formula

$\mathrm{LD}_{50}=\sqrt{ }($ Highest non-lethal dose $) \mathrm{x}$ (lowest lethal dose $)$

Formulation of creams. The formulation components are sorbitan monostearate and stearic acid which are melted in the liquid paraffin and cooled at $54^{\circ} \mathrm{C}$. The initial quantity of the extract used was $30 \mathrm{~g}$ and the weight of the beaker used when empty was $25.65 \mathrm{~g}$. The dissolution of all the quantity used was in 10 $\mathrm{ml}$. The methanol extract of Ficus platyphylla stem bark (MEFpSB) in different concentrations of $1 \%, 5 \%$ and $10 \%$ were determined. For $1 \%$, it was calculated as $1 / 30$ $\mathrm{x} 100$ and this gave $3.3 \mathrm{~g}$ which was weighed and mixed with propylene glycol $4.02 \% \mathrm{~W} / \mathrm{w}$, glycerin $4.13 \% \mathrm{w} / \mathrm{w}$ and $10 \mathrm{ml}$ of distilled water, all heated in one beaker till dissolution and this were allowed to cool to a room temperature. This procedure was also repeated for $5 \%$ and $10 \%$ respectively. Others like acetyl alcohol $3.56 \% \mathrm{w} / \mathrm{w}$, stearic acid $4.80 \%$ $\mathrm{w} / \mathrm{w}$, olive oil $5.78 \%$, span $601.78 \% \mathrm{w} / \mathrm{w}$ and tween $80 \quad 0.75 \% \mathrm{w} / \mathrm{w}$ were also heated in different beaker and all finally dissolved, stirred together until it cooled. The creams were then separated in different transparent container for onward use for the wound healing activities.

Antimicrobial assessment. The antimicrobial activity of methanol extract of $F$. platyphylla stem bark (MEFpSB) was determined using the following pathogenic microorganisms 
(Staphylococcus aureus, Streptococcus pyogenes, Corynebacterium ulcerans, Proteus mirabilis, Pseudomonas florescence, Klebsiella pneumonia and Salmonella typhi). The microbes were obtained from the Directorate of Research and Development, Nigerian Institute of Leather Research and Technology (NILEST), Zaria. $0.6 \mathrm{~g}$ of MEFpSB was weighed and dissolved in $10 \mathrm{ml}$ of distilled water so as to obtain a concentration of $60 \mathrm{mg} / \mathrm{ml}$. This was the initial concentration used to check the antimicrobial activities of the plant. Mueller Hinton agar was the medium used as the growth medium for the microbes. The medium was prepared according to manufacturer's instruction sterilized at $121^{\circ} \mathrm{C}$ for $15 \mathrm{~min}$. The medium was poured into sterile Petri-dish, the plates were then allowed to cool and solidify. Diffusion method was the method employed for the screening of the extract. The sterilized medium was then seeded with $0.1 \mathrm{ml}$ of the standard inoculums of the test microbes. The inoculum was spread evenly over the surface of the medium with a sterile swab. By the use of a standard cork borer of $6 \mathrm{~mm}$ in diameter, a well was cut at the center of each inoculated medium. $0.1 \mathrm{ml}$ of the extract solution in concentration of $60 \mathrm{mg} / \mathrm{ml}$ was then introduced into each well on the inoculated medium. The inoculated plates were incubated at $37^{\circ} \mathrm{C}$ for 24 $\mathrm{h}$, after which each plate was observed for zone of inhibition of growth. The zone was measured with a transparent ruler and the results recorded in millimeter .

Minimum inhibitory concentration (MIC). The minimum inhibitory concentration (MIC) of MEFpSB was carried using broth dilution method [17]. Mueller Hinton broth was prepared, $10 \mathrm{ml}$ was dispensed into test tubes and was sterilized at $121^{\circ} \mathrm{C}$ for $15 \mathrm{~min}$, and the broth was then allowed to cool. McFarland's turbidity standard scale number $0-5$ was prepared to give turbid solution. Normal saline was prepared, $10 \mathrm{ml}$ was dispersed into sterile test tube and the test microbe was inoculated and incubated at $37^{\circ} \mathrm{C}$ for 6 hours. Dilution of the test microbe in the normal saline was done until the turbidity marched that of the McFarland's standard by visual comparison; at this point the test microbe has a concentration of about $1.5 \times 108 \mathrm{cfu} / \mathrm{ml}$ (colony-forming unit $/ \mathrm{ml}$ ). Two fold serial dilution of the MEFpSB in the sterilized broth was made to obtain the concentration of $60 \mathrm{mg} / \mathrm{ml}, 30$ $\mathrm{mg} / \mathrm{ml}, 15 \mathrm{mg} / \mathrm{ml}, 7.5 \mathrm{mg} / \mathrm{ml}$ and $3.75 \mathrm{mg} / \mathrm{ml}$. The initial concentration was observed by dissolving $0.6 \mathrm{~g}$ of the MEFpSB in $10 \mathrm{ml}$ of the sterile broth. On obtaining the different concentrations of the MEFpSB in the broth, 0.1 $\mathrm{ml}$ of the test microbe in the normal saline was then inoculated into the different concentrations. Incubation was made at $37^{\circ} \mathrm{C}$ for $24 \mathrm{~h}$ after which the test tube was observed for turbidity (growth), the lowest concentration of the MEFpSB in the broth which shows no turbidity was recorded as the MIC.

Minimum bactericidal concentration (MBC). The MBC was carried out following the method of Celiktas et al., 2007 [17] to check whether the test microbes were killed or only the growth was inhibited. The Mueller Hinton agar was prepared, sterilized and was poured into sterile petri-dishes and the plate were allowed to cool and solidify. The content of the $\mathrm{MBC}$ in the serial dilutions were then sub-cultured onto the prepared medium, incubation was made at $37^{\circ} \mathrm{C}$ for $24 \mathrm{~h}$, after which each plate was observed for colony growth. The MBC was the plate with the lowest concentration of the extract without colony growth.

Wound healing studies. An excision wound healing model was used as described by Nayak et al., 2007 [18]. The rats were weightmatched and placed into six (6) group ( $\mathrm{n}=5)$, but the rats in the same group were also separated in different cages after excision to prevent cannibalism and subsequent application of cream prepared for wound healing at the dorsal region where excision was made. The dorsal fur of the animal was shaved 
with a razor blade and the area of the wound to be created was outlined on the back of the animals using permanent marker. All rats used for the experiment were anaesthetized with lidocaine at the region of the excision and a full thickness excision wound of $1 \mathrm{~cm}$ in width was created along the markings using toothed forceps, a surgical blade and pointed scissors in Department of Pharmacology Laboratory, A.B.U Zaria. Group I rats served as control and was treated with base cream only, while groups II, III, IV were treated with cream extract of 1 $\%, 5 \%$ and $10 \% \mathrm{w} / \mathrm{w}$ of the animal in each group measured. Group V served as synergism group and was treated with the cream $1 \%$ silver sulfadiazine $+10 \%$ extract $\mathrm{w} / \mathrm{w}$. Group VI served as standard and was treated with $1 \%$ silver sulfadiazine only. All the treatment lasted for eleven (11) days and wound area measurements were taken using caliper, thread and ruler on days $3,5,7,9$, and 11. All the animals were left for observation for two (2) weeks post complete wound closure and healing for any observable signs of toxicities. The percentage wound healing was calculated using the formula below:

\footnotetext{
$\%$ Wound Healing $=\{($ Initial wound area - Unhealed wound area) $\div$ Initial wound area $\}$ X 100
}

Statistics. All experiments were performed in replicates $(n=3)$ for validity of statistical analysis. Results were expressed as mean \pm standard error of mean (S.E.M.). One way analysis of variance (ANOVA) and student ttests were performed on data set using SPSS analytical tool. Values of $\mathrm{p}<0.05$ were considered significant.

\section{RESULTS}

Phytochemical screening. The results of preliminary phytochemical screening show the presence of carbohydrate, cardiac glycoside, saponin, flav noids, triterpenes, tannins, alkaloids but anthraquinones was absent (Table 1)
Effects of methanol extract of $F$. platyphylla stem bark (MEFpSB) on the studied microbes. The results of antimicrobial susceptibility effects of MEFpSB and $1 \%$ silver sulfadiazine against the tested organisms (Staphylococcus aureus, Streptococcus pyogenes, Corynebacterium ulcerans, Escherichia coli, Proteus mirabilis, Pseudomonas flourescense, Klebsiella pneumonia and Salmonella typhi) showed that the microbes Staphylococcus aureus, Corynebacterium ulcerans, Escherichia coli, Klebsiella pneumonia and Salmonella typhi are sensitive to MEFpSB but the microbes Streptococcus pyogenes, Proteus mirabilis and Pseudomonas flourescense were resistance to MEFpSB. Meanwhile, the microbes Corynebacterium ulcerans, Escherichia coli, Klebsiella pneumonia and Salmonella typhi were sensitive to $1 \%$ silver sulfadiazine but Staphylococcus aureus, Streptococcus pyogenes, Proteus mirabilis and Pseudomonas flourescense were resistant to $1 \%$ silver sulfadiazine (Table 2).

Effects of methanol extract of Ficus platyphylla stem bark (MEFpSB) and $1 \%$ silver sulfadiazine on zone of inhibition on test microbes. The results of zone of inhibitions of the MEFpSB against the tested microbes (Staphylococcus aureus, Streptococcus pyogenes, Corynebacterium ulcerans, Escherichia coli, Proteus mirabilis, Pseudomonas flourescense, Klebsiella pneumoniae and Salmonella typhi) showed respectively as 22, 0, 24, 20, 0, 0, 27 and 20 all in millimeters (mm). Also for $1 \%$ silver sulfadiazine against the microbes (Staphylococcus aureus, Streptococcus pyogenes, Corynebacterium ulcerans, Escherichia coli, Proteus mirabilis, Pseudomonas flourescense, Klebsiella pneumonia and Salmonella typhi) are respectively 0, 0, 32, 29, 0, 0, 35 and 27 (Table $3)$. 
Effects of minimum inhibitory concentration (MIC) and antimicrobial susceptibility using MEFpSB. For MIC, the results showed that Staphylococcus aureus, Corynebacterium ulcerans, Escherichia coli and Salmonella typhi were inhibited by the MEFpSB at $15 \mathrm{mg} / \mathrm{ml}$ turbidity and of slight growth at $7.5 \mathrm{mg} / \mathrm{ml}$ with moderate turbidity at $3.75 \mathrm{mg} / \mathrm{ml}$ respectively. Streptococcus pyogenes, Proteus mirabilis and Pseudomonas flourescense were not inhibited by the extract. Lastly, Klebsiella pneumoniae has the minimum inhibition concentration of 7.5 $\mathrm{mg} / \mathrm{ml}$ when treated with the extract and turbidity of $3.5 \mathrm{mg} / \mathrm{ml}$ was also observed (Tabled 4)

Effects of minimum bactericidal concentration (MBC) on test microbes using MEFpSB. The MBC results showed that the methanol extract of $F$. platyphylla stem bark (MEFpSB) can kill the microbes Staphylococcus aureus, Corynebacterium ulcerans, Escherichia coli, Klebsiella pneumoniae and Salmonella typhi at a minimum bactericidal concentration of 30 $\mathrm{mg} / \mathrm{ml}, 30 \mathrm{mg} / \mathrm{ml}, 60 \mathrm{mg} / \mathrm{ml}, 15 \mathrm{mg} / \mathrm{ml}$ and 60 $\mathrm{mg} / \mathrm{ml}$ respectively. This means that the extract will kill these microbes completely at this concentration stated in their respective regions. The extract has no effects on Streptococcus pyogenes, Proteus mirabilis, Pseudomonas fluorescence and Klebsiella pneumonia (Table 5)
Effects of topical application of MEFpSB cream extract on excision wound in rats treated for 11 days. The topical application of $1 \%$ MEFpSB cream showed that there was no statistical ( $p>0.05$ ) difference at day 3 $(0.80 \pm 0.03)$ compared to the base formulation $(0.86 \pm 0.02)$, but there was statistical $(p<$ $0.001)$ decrease at day $3 \quad(0.56 \pm 0.05$, $0.48 \pm 0.04$ ) of the cream extract $5 \%$ and $10 \%$ respectively in relation to the wound area when compared to the base formulation $(0.86 \pm 0.02)$ with the $5 \%$ and $10 \%$ showing $100 \%$ effectiveness in the healing of the wound. The standard drug ( $1 \%$ silver sulfadiazine) offered effectiveness of $100 \%(0.56 \pm 0.05)$ also at day 3 . At day 5 , extract $1 \%$ preparation had statistical $(p<0.05)$ decrease $(0.52 \pm 0.04)$ while that of $5 \%, 10 \%$ cream extract had statistical $(p<0.001)$ difference $(0.38 \pm 0.04,0.24 \pm 0.03)$. This showed that at day 5,1\% cream extract had $95 \%$ wound healing effectiveness while 5 $\%$ and $10 \%$ had $100 \%$ wound healing effectiveness (Table 6). The standard silver sulfadiazine had also $100 \%$ wound healing effectiveness. At both day 7 and 9, there was statistical difference $(p<0.001)$ showing 100 $\%$ wound healing effectiveness of all the percentage cream extracts. At day 11, there was statistical $(p<0.05)$ difference in all the cream percentage extract used for the excision sites on the Wistar rats (Table 6).

Table 1: Phytochemical constituents of methanol extract of $F$. platyphylla stem bark.

\begin{tabular}{cc}
\hline Constituents & Remark \\
\hline Carbohydrate & Present \\
Saponins & Present \\
Tannins & Present \\
Flavanoids & Present \\
Triterpenes & Present \\
Alkaloids & Present \\
Anthraquinones & Absent \\
\hline
\end{tabular}


Table 2: Antimicrobial susceptibility effect of methanol extract of Ficus platyphylla stem bark (MEFpSB) and $1 \%$ silver sulfadiazine

\begin{tabular}{llc}
\hline \multicolumn{1}{c}{ Test Organism } & MEFpSB & Silver sulfadiazine cream \\
\hline Staphylococcus aureus & Sensitive & Resistant \\
Streptococcus pyogenes & Resistant & Resistant \\
Corynebacterium ulcerans & Sensitive & Sensitive \\
Escherichia coli & Sensitive & Sensitive \\
Proteus mirabilis & Resistant & Resistant \\
Pseudomonas flourescense & Resistant & Resistant \\
Klebsiella pneumoniae & Sensitive & Sensitive \\
Salmonella typhi & Sensitive & Sensitive \\
\hline
\end{tabular}

Table 3: Effects of Methanol extract of Ficus platyphylla stem bark (MEFpSB) and $1 \%$ silver sulfadiazine on zone of inhibition on test microbes

\begin{tabular}{lcc}
\hline \multirow{2}{*}{ Test Organism } & \multicolumn{2}{c}{ Zone of inhibition (mm) } \\
\cline { 2 - 3 } & MEFpSB & Silver sulfadiazine cream \\
\hline Staphylococcus aureus & 22 & 0 \\
Streptococcus pyogenes & 0 & 0 \\
Corynebacterium ulcerans & 24 & 32 \\
Escherichia coli & 20 & 29 \\
Proteus mirabilis & 0 & 0 \\
Pseudomonas flourescense & 0 & 0 \\
Klebsiella pneumoniae & 27 & 35 \\
Salmonella typhi & 20 & 27 \\
\hline
\end{tabular}

Table 4: Minimum inhibitory concentration (MIC) $(\mathrm{mg} / \mathrm{ml})$ and antimicrobial susceptibility effect of MEFpSB against test microbes

\begin{tabular}{lccccc}
\hline \multicolumn{1}{c}{ Test organism } & 60 & 30 & 15 & 7.5 & 3.75 \\
\hline Staphylococcus aureus & - & - & $0 *$ & + & ++ \\
Streptococcus pyogenes & - & - & $0 *$ & + & ++ \\
Corynebacterium ulcerans & - & - & $0 *$ & + & ++ \\
Escherichia coli & - & - & $0 *$ & + & ++ \\
Proteus mirabilis & - & - & - & - & - \\
Pseudomonas flourescense & - & - & - & - & - \\
Klebsiella pneumonia & - & - & - & $0 *$ & + \\
Salmonella typhi & - & - & $0 *$ & + & ++ \\
\hline
\end{tabular}

- = No turbidity (no growth), $0^{*}=$ Minimum Inhibitory Concentration, $+=$ Turbidity (high growth), ++ = Moderate

Turbidity, MIC = Minimum Inhibitory Concentration

Table 5: Minimum bactericidal concentration (MBC) of Ficus platyphylla on test microbes

\begin{tabular}{lccccc}
\hline \multicolumn{1}{c}{ Test organism } & 60 & 30 & 15 & 7.5 & 3.75 \\
\hline Staphylococcus aureus & - & $0 *$ & + & ++ & +++ \\
Streptococcus pyogenes & - & - & - & - & - \\
Corynebacterium ulcerans & - & $0^{*}$ & + & ++ & +++ \\
Escherichia coli & $0^{*}$ & + & ++ & +++ & ++++ \\
Proteus mirabilis & - & - & - & - & - \\
Pseudomonas flourescense & - & - & - & - & - \\
Klebsiella pneumoniae & - & - & $0^{*}$ & + & ++ \\
Salmonella typhi & $0^{*}$ & + & ++ & +++ & ++++ \\
\hline
\end{tabular}

- =No turbidity i.e. no growth, $0 *=$ Minimum bactericidal concentration, $+=$ Scanty colonies growth, $++=$ Moderate colonies growth, $+++=$ Heavy colonies growth 
Table 6: Effects of topical application of Ficus platyphylla cream extract on excision wound in rats treated for 11days

\begin{tabular}{cccccc}
\hline \multirow{2}{*}{$\begin{array}{c}\text { Cream } \\
(\% \mathrm{w} / \mathrm{v})\end{array}$} & Day 3 & Day 5 & Day 7 & Day 9 & Day 11 \\
\cline { 2 - 6 } Base & $0.86 \pm 0.02$ & $0.68 \pm 0.04$ & $0.56 \pm 0.04$ & $0.42 \pm 0.02$ & $0.30 \pm 0.03$ \\
Ext. 1\% & $0.80 \pm 0.03^{\mathrm{n}}$ & $0.52 \pm 0.04^{\mathrm{a}}$ & $0.36 \pm 0.02^{\mathrm{c}}$ & $0.12 \pm 0.01^{\mathrm{c}}$ & $0.06 \pm 0.02^{\mathrm{a}}$ \\
Ext. 5\% & $0.56 \pm 0.05^{\mathrm{c}}$ & $0.38 \pm 0.04^{\mathrm{c}}$ & $0.22 \pm 0.02^{\mathrm{c}}$ & $0.13 \pm 0.03^{\mathrm{c}}$ & $0.06 \pm 0.02^{\mathrm{a}}$ \\
Ext. 10\% & $0.48 \pm 0.04^{\mathrm{c}}$ & $0.24 \pm 0.03^{\mathrm{c}}$ & $0.16 \pm 0.02^{\mathrm{c}}$ & $0.10 \pm 0.03^{\mathrm{c}}$ & $0.12 \pm 0.10^{\mathrm{a}}$ \\
$1 \%$ Dermazin & $0.56 \pm 0.05^{\mathrm{c}}$ & $0.38 \pm 0.04^{\mathrm{c}}$ & $0.22 \pm 0.02^{\mathrm{c}}$ & $0.13 \pm 0.01^{\mathrm{c}}$ & $0.06 \pm 0.02^{\mathrm{a}}$ \\
\hline
\end{tabular}

Values are expressed in Mean \pm SEM, $n=5$, ns=not significant, $\mathrm{df}=$ degree of freedom, $\mathrm{f}=$ frequency, $\alpha=$ degree of significant, $\mathrm{p}<0.05^{\mathrm{a}}, \mathrm{p}<0.001^{\mathrm{b}}$ and $\mathrm{c}$ One Way ANOVA followed by Dunnet's t-test.

\section{DISCUSSION}

Some medicinal plants were scientifically proven to be used for the healing of wounds which are mentioned in the African folk medicine $[19,20]$. Plants have the ability to synthesize aromatic substances, most of which are phenolic compounds and their oxygen-substituted derivatives [21]. In many cases, these substances serve as plant defense mechanisms against predation by microorganisms, insects, and herbivores while some, such as terpenoids, give plants their odors; others (quinones and tannins) are responsible for plant pigment [22]. The mode of action for plant-derived agents targets biochemical features of the invading pathogens that are not possessed by the normal host cell. Sensitivity of the infecting micro-organism to a particular agent is some of the factors important for antimicrobial treatment [23].

Phytochemical constituents present in plants are said to be active secondary metabolites responsible for the important pharmacological activities and they play a major role in wound healing. For example, tannins have been shown as an active detoxifying agent and also inhibit bacterial growth [24]. Also the astringent and antimicrobial property of terpenoids have been said to promote the wound healing process [25] and flavonoids are said to be potent antioxidants, free radical scavengers [14, 26, 27]. Polyphenols and flavonoids which prevent the synthesis of prostaglandins are said to possess anti-inflammatory properties and have antimicrobial activities [28]. Glycosides isolated from plants are also said to possess antioxidant, antimicrobial, analgesic, antitumor, immunomodulatory, and antiinflammatory effects $[29,30]$. Therefore, the presence of phytochemicals in the crude extract of our plant such as terpenoids, flavonoids, glycosides, saponins, tannins, and phenolic compounds may have contributed to the wound healing activities serving as detoxifying agent with the inhibition of the bacterial growth [24], fast promotion of the wound healing [25], acting as an antiinflammatory agent (30) as shown in the previous work using the plant (Fp), antioxidant and antimicrobial $[14,25,30]$ on the Wistar rats.

The presence of pathogenic organisms such as Staphylococcus aureus, Corynebacterium ulcerans, Escherichia coli, Klebsiella pneumonia and Salmonella typhi in wounds have been shown to result in infection of wounds which may lead to formation of chronic wounds [31]. The study showed that the extract exhibited strong broad spectrum antimicrobial activity against these pathogens (Table 2). The extract has been shown to be sensitive to Staphylococcus aureus, Corynebacterium ulcerans, Escherichia coli, Klebsiella pneumonia and Salmonella typhi hence preventing the wound from getting infected with microbes [31, 32]. The topical application of antimicrobial agents/extract is an efficient method of microbial populations' destruction because of the availability of the active agents at the wound site which led to enhanced wound healing activity (32). The 
MEFpSB had significant influence on the rate of wound closure based on different days of treatment of the wounds with the extract compared with the base cream treated group and the standard. The $5 \%$ cream extract had the same strength compared to the standard 1 $\%$ silver sulphadiazine at day 3 . At day 5 there were significant wound contraction $(p<0.001)$ which showed the same in day 7 and day 9 and wound closure of $81.56 \%, 80.85 \%$ and 88.9 $\%$ for $1 \%$ cream extract respectively. Also there was different percentage wound closure for $5 \%$ and $10 \%$ cream extract as shown in the result. The wound of the Wistar rats treated with base cream showed no statistical $(p>$ 0.05) difference compared to the cream extracts $(1 \%, 5 \%$ and $10 \%$ cream preparations) and standard, $1 \%$ silver sulphadiazine treated wounds. This may also indicate that the components of the base cream do not interfere with the activities of the extract hence the enhanced effectiveness of the MEFpSB which may be primarily due to the bioactive principles present in the extract [13]. The above findings may support the claims that wound healing process may be due to their direct action on the wound repair process, phytochemical bioactive present and antimicrobial effects or the combination of the above effects [18].

Conclusion. This study has shown that $M E F p S B$ has phytochemical constituents which have the ability in wound healing therapy of the wound on the Wistar rats. The effectiveness of the extract in wound healing may also be attributed to its earlier study showing its anti-inflammatory and antioxidant effects with good potent antimicrobial ability as shown in this our present studies.

\section{REFERENCES}

1. Huxley A. The New RHS Dictionary of Gardening. MacMillan Press. 1992. ISBN: 0-33347494-5

2. Global Invasive Species Database. 2000. https//www.issg.org/database/welcome/
3. Burkil HM. The useful plants of West Tropical Africa. Royal Botanic Gardens. Kew. 2004. http://www.aluka.org/

4. Uphof JCTh. The Dictionary of Economic Plants. Weinheim. 1959; 591, 25. www.abebooks.com

5. Von Maydell H. Trees and Shrubs of the Sahel. Their characteristics and uses. Deutsche Gesllschaft for Technische Zusammenabeit: Germany. 1990. ISBN: 3-8236-1198-4.

6. Robinson M.M and Zhang X. The world medicines situation, Trad. Med: Global situation, issues and challenges, World Health Organization, Geneva, Switzerland. 2011; $3^{\text {rd }}$ Ed.

7. Haile and Delenasaw. Traditional medicinal plant knowledge and use by local healers in Seoru District, Jimma zone, Southwestern Ethiopia. J of Ethnobio and Ethnomed. 2007; 3 (1):24.

8. Adesina SK. African mistletoes (Loranthaceae); Ethnopharmacol, chemistry and Medicinal values. 2013;10(4):161-70

9. Audu JA. Medicinal plants and their use in Bauchi State. Nigeria Field. 1989; 54, 157-168.

10. Chindo BA, Anuka JA, Lees G, Yaro AH, Adamu SS, Amos S, Wambebe C, Gamaniel KS. Psychopharmacological properties of the saponin fraction of Ficus platyphylla stem bark. Inter J of Biol and Chem Sci. 2008; 2 (3), 239-248.

11. Chindo BA, Schroder H, Koeberle A, Werz O, Becker A. Analgesic potential of standardized methanol stem bark extract of Ficus platyphylla in mice; Mechanisms of actions. J Ethnopharmacol. 2016; 184: 101-106.

12. Chindo BA, Yau J, Danjuma NM, Okhale ES, Gamaniel SK and Becker K. Behavioural and Anticonvulsant effects of the standardized extract of Ficus platyphylla stem bark. J Ethnopharmacol. 2014, 154: 351-360.

13. Chindo BA, Anuka JA, Gamaniel KS. Toxicity screenings of Ficus platyphylla stem bark in rats, Pharmacologia. 2012a; 3, 499-505.

14. Sheidu AR, Umar ZA, Abubakar A, Ahmed CB, Garba MM, Ogere AI, Murtala SO. Antioxidant and Hepatoprotective Potentials of Methanol Extract of Ficus platyphylla Stem Bark Delile (Moraceae) in Wistar Rats. Trop J Nat Prod Res. 2020; 4(3):91-97.

15. Evans WC. Trease and Evans Pharmacognosy. $15^{\text {th }}$ Ed. Saunders WR, London. $2002233-336$. 
16. Lorke D. A new approach to acute toxicity testing; Arch. Toxicol., 1983; 54, 275-287

17. Celiktas OY, Kocabas EEH, Bedir E, Sukan FV, Ozek T and Baser KHC. "Antimicrobial activities of methanol extracts and essential oils of rosmarinus officinalis, depending on location and seasonal variations," Food Chemistry. 2007; 100(2), 553-559.

18. Nayak BS, Anderson M, Periara LM and Pinto. Evaluation of wound healing potency of Catharanthus roseus leaf extract in rats. Fitoterapia, 2007; 78: 540544.

19. John-Africa LB, Yahaya TA and Isimi CY. Anti-ulcer and Wound healing activities of Sida corymbosa in Rats. Afri J of Trad, Complem and Alter Med. 2014; 11(1), 87- 92.

20. Sabale P, Bhimani B, Prajapati C and Sabalea $\mathrm{V}$. "An overview of medicinal plants as wound healers," J of Applied Pharma Sci. 2012; 2(11):143150 .

21. Vidhya $\mathrm{R}$ and Udayakumar R. Antifungal efficacy of leaf, flower and root of Aervan lanata (Linn.) against selected fungal pathogens. J immunol Clin Microbiol, 2017; 2(1),7-13

22. Redondo ML, Chacana AP, Dominguez EF and Miyakawa FEM. Perspectives in the use of tannins as alternative to antimicrobial growth promoter factors in poultry. Review Article. Front. Microbiol. 2014; 5:118.

23. Ahmad I, Beg A. Z. Antimicrobial and phytochemical studies on 45 Indian medicinal plants against multi-drug resistant human pathogens. $J$ of Ethnopharmacol. 2001; 74(2): 113-23.

24. Khemiri I, Hedi EB, Zouaoui SN, Gdara BN and Bitri L. The Antimicrobial and Wound Healing Potential of Opuntia ficus indic L. intermis Extracted oil from Tunisia. Evi. Base Compli. and Alter. Med. Hindawi; 2019. ID 9148782.

25. Bodenstein J and Du Toit K. The Susceptibility of Staphylococcus Aureus and Klebsiella Pneumoniae to Naturally Derived Selected Classes of Flavonoids. 2012. DOI: $10.5772 / 47948$.

26. Getie M, Gebre-Mariam T, Rietz R et al., "Evaluation of the anti-microbial and antiinflammatory activities of the medicinal plants Dodonaea viscosa, Rumex nervosus and Rumex abyssinicus," Fitoterapia, 2003; 74 (1): 139-143.

27. Arun M, Satish S and Anima P. "Evaluation of wound healing, antioxidant and antimicrobial efficacy of Jasminum auriculatum Vahl. leaves," Avicenna J of Phytomed. 2016; 6(3): 295-304.

28. Armstrong DG and Jude EB. "The role of matrix metalloproteinases in wound healing," $J$ of the American Podiatric Med. Assoc. 2002; 92(1): 12-18.

29. Kipngeno DC, Mshimba SM and Gilbert C. "Antimicrobial activity and phytochemical investigation of crude extracts of the fruits of Solanum incanum (Solananceae) and Dovyalis abbysinica (Flacourtiaceae)," Sci J of Microbiol. 2014, ISSN: 2276-626X. www.sjpub.org/sjmb.html

30. Demilew W, Adinew MG and Asrade S. Evaluation of the Wound Healing Activity of the Crude Extract of Leaves of Acanthus polystachyus Delile (Acanthaceae). Evid. Base Compli. and Alter. Med., 2018; 8,9.

31. Diegelmann RF and Evans MC. Wound healing: an overview of acute, fibrotic and delayed healing. Front. Biosci., 2014; 9:283-289.

32. Gardner SE and Frantz RA. Wound bioburden and infection-related complications in diabetic foot ulcers. Biol Res Nurs. 2008; 10:44-53. 